\title{
Evapotranspiração de referência nos perímetros irrigados do Estado de Sergipe
}

\author{
Inajá F. de Sousa ${ }^{1}$, Vicente de P. R. da Silva ${ }^{2}$, Fabiana G. Sabino ${ }^{1}$, Antenor de 0. A. Netto ${ }^{1}$, \\ Bruce K. N. Silva ${ }^{1} \&$ Pedro V. de Azevedo²
}

\section{RESU MO}

0 conhecimento da evapotranspiração de referência $\left(E_{0}\right)$ é essencial no manejo de irrigação de culturas agrícolas em todo 0 mundo. Neste trabalho se utilizaram dados meteorológicos diários de evaporação do tanque "Classe A", temperaturas máximas e mínimas, insolação, velocidade do vento a $2 \mathrm{~m}$ de altura e umidade relativa do ar, referentes ao período de 1989 a 1993, coletados em quatro perímetros irrigados do Estado de Sergipe, para estimativa da $\mathrm{ET}_{0}$ com base nos métodos do Tanque Classe "A", Radiação Solar, Hargreaves \& Samani, Linacre e Penman-Monteith (FA0/56). Comparam-se os valores diários da $\mathrm{ET}_{0}$ para a região estudada, através dos quais, quando comparados com o modelo de Penman-M onteith (FAO/56) se obtiveram os melhores desempenhos com os métodos que utilizam a radiação solar como dado de entrada no modelo. 0 método do Tanque Classe " $\mathrm{A}$ " não apresentou desempenho satisfatório em nenhum perímetro irrigado estudado.

Palavras-chave: demanda hídrica, evaporação, método de Penman-M onteith, planejamento de irrigação

\section{Reference evapotranspiration in the irrigated perimeters of the State of Sergipe}

\begin{abstract}
The knowledge of reference evapotranspiration $\left(E T_{0}\right)$ is essential for the irrigation scheduling of crops throughout the world. This work used daily meteorological data of Class A pan evaporation, maximum and minimum air temperatures, insolation, wind speed at $2 \mathrm{~m}$ above surface and relative humidity from 1989 to 1993 for four irrigated perimeters of Sergipe. These data were used for estimating $\mathrm{ET}_{0}$ based on the following methods: Class A pan evaporation, Solar Radiation, Hargreaves \& Samani, Linacre and Penman-M onteith (FAO/56). The daily values of $\mathrm{ET}_{0}$ were compared to those obtained by FAO Penman-Monteith method in order to choose the best method of estimating $\mathrm{ET}_{0}$ for the region. The best performance was obtained for those models which used the solar radiation as the data input. The Class A pan evaporation method did not show favorable performance in any irrigated perimeter.
\end{abstract}

Key words: water requirements, evaporation, Penman-M onteith method, irrigation scheduling.

${ }^{1}$ DEA/UFS, Cidade Universitária Prof. José Aloísio de Campos, CEP 49100-000, São Cristóvão, SE. Fone: (79) 2105-6929. E-mail: ifsousa@ufs.br; antenor@ufs.br; sabino@hotmail.com.br

2 UACA/UFCG, Av. Aprígio Veloso, 882, Bodocongó, CEP 58109-970, Campina Grande, PB. Fone: (83) 3310-1202. E-mail: vicente@dca.ufcg.edu.br; pvieira@dca.ufcg.edu.br; brucekellys@yahoo.com.br 


\section{INTRODUÇÃO}

O conhecimento sobre o consumo hídrico das culturas, obtido com base na estimativa da evapotranspiração, constitui uma informação preciosa no manejo da água em qualquer região do planeta, principalmente agora em que ocorre forte conscientização popular em relação aos recursos hídricos, em referência a décadas anteriores (Campos et al., 2008). A ocorrência de períodos de longas estiagens na região semiárida brasileira, associada à alta disponibilidade de energia, favorece a redução do nível de água nos reservatórios tornando a agricultura de sequeiro uma atividade de alto risco.

A agricultura de subsistência, explorada por pequenos agricultores, não apresenta rentabilidade de modo a impedir a migração da população rural para os centros urbanos (Silva et al., 2002). Para manter o pequeno agricultor no campo e restaurar a produção agrícola, projetos de irrigação vêm sendo implantados em muitas regiões do semiárido brasileiro, os quais dividem o campo em lotes ou áreas produtivas distribuídas entre os pequenos agricultores, usufruindo de sistemas de irrigação apoiados em mananciais de grande capacidade. Em geral, não há nesses projetos uma preocupação maior com o uso racional dos recursos hídricos.

A estimativa adequada da evapotranspiração da cultura $\left(\mathrm{ET}_{\mathrm{c}}\right)$ consiste no principal parâmetro a ser considerado no dimensionamento e manejo de sistemas de irrigação, uma vez que ela totaliza a quantidade de água utilizada nos processos de evaporação e transpiração pela cultura, durante determinado período. De forma bastante simplificada, a $\mathrm{ET}_{\mathrm{c}}$ pode ser obtida através do valor da evapotranspiração de uma cultura de referência $\left(\mathrm{ET}_{\mathrm{o}}\right)$ corrigida pelo coeficiente da cultura $\left(\mathrm{K}_{\mathrm{c}}\right)$, que dependente do tipo de cultura e de seu estágio de desenvolvimento (Silva et al., 2009). Apesar da existência de diversos modelos para se estimar a $\mathrm{ET}_{\mathrm{o}}$, eles, no entanto, são utilizados em condições climáticas e agronômicas muito diferentes, em função da disponibilidade de dados climáticos.

A evapotranspiração de referência é uma variável relevante para o planejamento de irrigação, além de fácil obtenção haja vista ser afetada apenas pelos fatores climáticos. Em geral, os métodos de estimativa da evapotranspiração de referência são baseados em variáveis climáticas, muitos deles na temperatura, radiação ou combinado (radiação e temperatura) (Penman, 1948; Thornthwaite, 1948; Priestley \& Taylor, 1972; Hargreaves, 1974). Para padronizar o cálculo de $\mathrm{ET}_{\mathrm{o}}$, a Food and Agriculture Organization (FAO) propôs o método de Penman-Monteith, com base em estudos de uma comissão de especialista em 1991, que incorpora aspectos termodinâmico e aerodinâmico da cultura, como modelo padrão para quantificar a demanda atmosférica de evapotranspiração. Este método, que tem sido amplamente utilizado em todo o mundo (Silva, 2004; Silva et al., 2005; Borges \& Mendiondo, 2007), foi estabelecido para uma cultura hipotética com as seguintes características: resistência estomática de $70 \mathrm{~s} \mathrm{~m}^{-1}$, altura da cultura hipotética fixada em $0,12 \mathrm{~m}$ e albedo de 23\% (Allen et al., 1998).

Borges \& Mendiondo (2007) verificaram a precisão dos métodos de estimativa de $\mathrm{ET}_{\mathrm{o}}$ propostos por Camargo, Bla-
ney-Criddle, Hamon, Hargreaves, Thornthwaite e Kharrufa, para a bacia do rio Jacupiranga, SP, Brasil. Na comparação das equações com o método FAO Penman-Monteith, os resultados obtidos indicaram que a equação de Hargreaves apresentou índices de confiança superiores a 0,995 para a bacia estudada e ela foi recomendada devido às suas exequibilidade e simplicidade; por outro lado, Suleiman \& Hoogenboom (2007) compararam o método de Priestley-Taylor com o de Penman-Monteith (FAO/56) na estimativa da $\mathrm{ET}_{\mathrm{o}}$ diária na Geórgia, Estados Unidos. Os resultados deste trabalho indicaram que os valores de $\mathrm{ET}_{\mathrm{o}}$ obtidos pelo método de Priestley-Taylor subestimam os valores em relação à equação de Penman-Monteith durante os meses de inverno, nas áreas central e sudoeste e os superestimam nas áreas costeiras e montanhosas. Stone \& Silveira (1995) compararam nove modelos de estimativa de $\mathrm{ET}_{\mathrm{o}}$ com os resultados obtidos a partir da evaporação do tanque "Classe A para o município de Santo Antônio de Goiás", GO e, com base nos resultados obtidos, verificaram que o modelo de Penman foi o que apresentou maior coeficiente de correlação com os valores medidos pelo tanque "Classe A", seguido dos modelos de Hargreaves e Garcia-Lopez; esses dois últimos modelos empregam, na sua formulação, a umidade relativa, sendo a variável climática que mais influenciou na evaporação do tanque "Classe A", o que justifica a alta correlação dos valores medidos e estimados de $\mathrm{ET}_{\mathrm{o}}$.

Os métodos para a estimativa da $\mathrm{ET}_{\mathrm{o}}$ são baseados em uma ou mais variáveis atmosféricas, tais como temperatura do ar, radiação solar e umidade relativa, e até mesmo em medições relacionadas com a própria variável (evaporação do tanque "Classe A"). Como o método de PenmanMonteith requer o maior número de variáveis atmosféricas na sua formulação, que muitas vezes não estão disponíveis em condições reais de manejo das culturas, alguns estudos têm sido desenvolvidos visando comparar outros métodos com o modelo padrão estabelecido pela FAO e dados experimentais em regiões específicas (Borges \& Mendiondo, 2007; Suleiman \& Hoogenboom, 2007).

$\mathrm{Na}$ ausência de dados meteorológicos a evaporação do tanque "Classe A" é amplamente utilizada para se estimar a evapotranspiração de referência, através de um coeficiente empírico que relaciona a evaporação do tanque com a evapotranspiração de referência (Allen et al., 1998). Na escolha de um método para determinação da evapotranspiração, deve-se levar em consideração a praticidade e a precisão, pois, apesar desses métodos teóricos e micrometereológicos se basearem em princípios físicos, eles apresentam limitações, principalmente quanto à instrumentação, o que pode restringir suas utilizações (Berlato \& Molion, 1981).

A grande maioria dos usuários da agricultura irrigada no Brasil não utiliza qualquer tipo de estratégia de uso e manejo racional da água na irrigação; além disso, o monitoramento automático ainda é muito incipiente; assim, o presente trabalho propõe uma contribuição ao uso racional dos recursos hídricos no manejo da irrigação dos perímetros irrigados do Estado de Sergipe. Efetivamente, o objetivo deste trabalho foi determinar a evapotranspiração de referência através de diversos modelos de estimativa e determinar o 
coeficiente do tanque classe "A" para os principais perímetros irrigados do Estado de Sergipe.

\section{MATERIAL E MÉTODOS}

Os perímetros irrigados analisados foram: Califórnia, Jabiberi, Jacarecica e Piauí, localizados em diferentes microrregiões do Estado de Sergipe (Tabela 1). Nessas áreas irrigadas são desenvolvidas atividades agrícolas por pequenos produtores, que contam com a assistência técnica agronômica e serviços de operação e manutenção prestados pela COHIDRO (Companhia de Desenvolvimento de Recursos Hídricos e Irrigação do Sergipe). As características de cada perímetro irrigado são mostradas a seguir.

Tabela 1. Relação das estações meteorológicas localizadas nos perímetros irrigados utilizadas no estudo

\begin{tabular}{lccc}
\hline Perímetros & Latitude (graus) & Longitude (graus) & Altitude (m) \\
Califórnia & 9,7 & 37,8 & 207 \\
J abiberi & 11,1 & 37,1 & 177 \\
J acarecica & 10,7 & 37,3 & 161 \\
Piauí & 10,9 & 37,7 & 160 \\
\hline
\end{tabular}

O perímetro Califórnia localiza-se no município de Canindé de São Francisco, no extremo noroeste do Estado de Sergipe, na Microrregião homogênea Sertão Sergipano do São Francisco, a $213 \mathrm{~km}$ de Aracaju. A área total desse perímetro é de 3.980 ha, dos quais 1.360 ha de áreas irrigadas com diferentes frutíferas e 1.830 ha de áreas com agricultura de sequeiro. Os solos do perímetro são dos tipos Luvissolos, Neossolos, Vertissolos, Cambissolos e Argissolos. A classificação climática, segundo Köppen, é do tipo Bssh (clima muito quente, semiárido, tipo estepe), com estação chuvosa centrada nos meses de abril, maio e junho. A precipitação pluviométrica média anual da região é de $483,9 \mathrm{~mm}$ e a temperatura média do ar está compreendida entre as isotermas 25 e $26{ }^{\circ} \mathrm{C}$, as temperaturas mínimas mensais entre 18 e $22{ }^{\circ} \mathrm{C}$ e as máximas mensais compreendidas entre 28 e $34{ }^{\circ} \mathrm{C}$ (Silva et al., 2003; Cavalcanti et al., 2006).

O perímetro irrigado Jabiberi localiza-se na região Sul do Estado de Sergipe, na Microrregião homogênea Sertão do Rio Real, no município de Tobias Barreto, a $123 \mathrm{~km}$ de Aracaju, $23 \mathrm{~km}$ da sede municipal e $149 \mathrm{~km}$ do litoral. A área total do perímetro é de 362 ha, sendo 220 ha de áreas irrigadas, com uma área média de 2,5 ha por lote, onde a exploração agrícola é baseada no cultivo de hortaliças (tomate e quiabo) e de grãos (principalmente milho e arroz). Neste perímetro predominam os solos Aluviais Eutróficos $(97,7 \%)$ e, em menor escala, os Plintossolos (12,3\%). Segundo a classificação climática de Köppen, o clima da área do projeto é do tipo As (clima quente, com temperatura do ar superior a $18{ }^{\circ} \mathrm{C}$ no mês mais frio e, no mês mais seco a precipitação pluvial é inferior a $60 \mathrm{~mm}$ e o verão é seco). A precipitação pluvial média anual em Jabiberi é de $756,9 \mathrm{~mm}$; o mês de julho é o mais frio do ano, com
$22,1{ }^{\circ} \mathrm{C}$, e o mês de janeiro é o mais quente, com média de $25,7{ }^{\circ} \mathrm{C}$; as temperaturas médias mínimas mensais estão compreendidas entre 18 e $22{ }^{\circ} \mathrm{C}$ e as temperaturas médias máximas mensais estão entre 26 e $32{ }^{\circ} \mathrm{C}$.

$\mathrm{O}$ perímetro irrigado Jacarecica se situa no município de Itabaiana, na parte central do Estado de Sergipe, na Microrregião homogênea do Agreste de Itabaiana; ele envolve terras que margeiam o rio Jacarecica, a oeste da serra de Itabaiana e a leste da sede municipal. Este perímetro se encontra a $65 \mathrm{~km}$ de Aracaju, $6 \mathrm{~km}$ da cidade de Itabaiana e $90 \mathrm{~km}$ para o litoral; sua área total é de 298 ha, sendo 252 ha de área irrigável. As principias culturas exploradas neste perímetro são: amendoim, batata-doce, milho verde, maxixe, pimentão, pepino, quiabo e tomate. A classificação climática de Köppen indica que o clima da área do subprojeto é do tipo As (clima quente, o mês mais frio apresenta temperatura do ar superior a $18{ }^{\circ} \mathrm{C}$ e o mês mais seco tem precipitação pluvial inferior a $60 \mathrm{~mm}$ e o verão é seco e quente). A precipitação pluvial média na área do Jacarecica é de $886,0 \mathrm{~mm}^{2} \mathrm{no}^{-1}$; enquanto a temperatura média do ar no mês mais frio do ano (julho) é de $22,5{ }^{\circ} \mathrm{C}$ e do mês mais quente (janeiro) é de $26,2{ }^{\circ} \mathrm{C}$. As temperaturas médias mínimas mensais estão compreendidas entre 27 e $32{ }^{\circ} \mathrm{C}$. De acordo com os estudos efetuados anteriormente, os solos da região são classificados como Planossolos.

O perímetro irrigado Piauí está localizado no município de Lagarto, na região Centro-Sul do Estado de Sergipe, na Microrregião Agreste de Lagarto, a $69 \mathrm{~km}$ de Aracaju, $6 \mathrm{~km}$ da sede municipal e $93 \mathrm{~km}$ para o litoral. A área do perímetro está totalmente inserida na bacia do rio Piauí, abrangendo uma superfície de 1.450 ha, sendo a área irrigável de 703 ha. As principais culturas exploradas são: amendoim, batata-doce, fumo, mandioca, pimentão, repolho, tomate e viveiros de citros. Segundo a classificação climática de Köppen, o clima da área do projeto é do tipo As, com precipitação média de $1.020,6 \mathrm{~mm}^{2} \mathrm{ano}^{-1} \mathrm{e}$ as temperaturas médias do ar dos meses mais frios ocorrem em julho e agosto, com valores em torno de $22,5^{\circ} \mathrm{C}$, e o mês mais quente é janeiro, com média de $26,2^{\circ} \mathrm{C}$. As temperaturas médias mínimas mensais estão compreendidas entre 18 e $22{ }^{\circ} \mathrm{C}$ e as temperaturas médias máximas mensais estão entre 26 e $32{ }^{\circ} \mathrm{C}$. Os solos prevalecentes nessa região são classificados como Podzólicos Vermelho Amarelo, Plintossolos e Planossolos Solódicos.

Utilizaram-se dados climáticos do período de 1989 a 1993, referentes aos valores diários de temperatura do ar (máxima, mínima e média), umidade relativa do ar (máxima, mínima e média), número de horas de brilho solar, velocidade do vento a $2 \mathrm{~m}$ acima da superfície e evaporação do Tanque Classe "A". Nas subseções a seguir são apresentadas as descrições de cada método utilizado no estudo.

\section{Método de Penman-Monteith - (PM)}

Obteve-se a evapotranspiração de referência $\left(\mathrm{ET}_{\mathrm{o}}\right)$ pelo método da FAO Penman-Monteith (PM) através da equação (Allen et al., 1998), considerando-se a resistência estomática de $70 \mathrm{~s} \mathrm{~m}^{-1}$, a altura da cultura hipotética de $0,12 \mathrm{~m} \mathrm{e}$ albedo de $23 \%$ : 


$$
\mathrm{ET}_{\mathrm{o}}=\frac{0,408 \Delta(\mathrm{Rn}-\mathrm{G})+\gamma\left(\frac{900 \mathrm{U}_{2}}{\mathrm{~T}+273}\right)\left(\mathrm{e}_{\mathrm{s}}-\mathrm{e}_{\mathrm{a}}\right)}{\Delta+\gamma\left(1+0,34 \mathrm{U}_{2}\right)}
$$

em que $\mathrm{ET}_{\mathrm{o}}$ é expresso $\mathrm{mm} \mathrm{d}^{-1}$, enquanto $\mathrm{R}_{\mathrm{n}}$ (saldo de radiação) e $\mathrm{G}$ (densidade do fluxo de calor no solo) são expressos em $\mathrm{MJ} \mathrm{m}^{-2} \mathrm{~d}^{-1}, \Delta$ é a declinação da curva de saturação do vapor da água $\left(\mathrm{kPa}^{\circ} \mathrm{C}^{-1}\right)$ e $\mathrm{U}_{2}$ é a velocidade do vento (média diária) a $2 \mathrm{~m}$ acima da superfície do solo $\left(\mathrm{m} \mathrm{s}^{-1}\right)$, T é a temperatura do ar $\left({ }^{\circ} \mathrm{C}\right)$, e $\mathrm{e}_{\mathrm{s}}$ é a pressão de saturação do vapor $(\mathrm{kPa}), \mathrm{e}_{\mathrm{a}}$ é a pressão real do vapor $(\mathrm{kPa})$ e $\gamma$ é o fator psicométrico $\left(\mathrm{MJ} \mathrm{kg}^{-1}\right)$.

\section{Método de Hargreaves - (HA)}

Por este método a evapotranspiração, em $\mathrm{mm} \mathrm{d}^{-1}$, foi estimada através da equação (Hargreaves, 1974):

$$
\mathrm{ET}_{\mathrm{o}}=0,0023\left(\mathrm{~T}_{\text {med }}+17,8\right)\left(\mathrm{T}_{\text {tmáx }}-\mathrm{T}_{\text {min }}\right)^{0.5} \mathrm{R}_{\mathrm{a}}
$$

em que $\mathrm{T}_{\text {med }}, \mathrm{T}_{\text {máx }}$ e $\mathrm{T}_{\text {mín }}$, em ${ }^{\circ} \mathrm{C}$, representam, respectivamente, as temperaturas média, máxima e mínima, e $\mathrm{R}_{\mathrm{a}}$ é a radiação solar no topo da atmosfera $\left(\mathrm{mm} \mathrm{d}^{-1}\right)$.

\section{Método de Linacre - (LI)}

A evapotranspiração de referência pelo método de Linacre, em $\mathrm{mm} \mathrm{d}^{-1}$, foi obtida em função da altitude, latitude e das temperaturas diárias máxima, mínima e do ponto de orvalho, pela equação (Linacre, 1977):

$$
\mathrm{ET}_{\mathrm{o}}=\frac{700 \frac{\mathrm{T}_{\mathrm{m}}}{(100-\phi)}+15\left(\mathrm{~T}_{\text {med }}-\mathrm{T}_{\mathrm{d}}\right)}{80-\mathrm{T}_{\text {med }}}
$$

em que:

$$
\begin{aligned}
\mathrm{T}_{\mathrm{m}} & =\mathrm{T}_{\text {med }}+0,006 \mathrm{z} \\
\mathrm{z} & - \text { é a altitude, } \mathrm{m} \\
\mathrm{T}_{\mathrm{med}} & - \text { é a temperatura média do ar, }{ }^{\circ} \mathrm{C} \\
\phi & - \text { a latitude local, graus } \\
\mathrm{T}_{\mathrm{d}} & - \text { é a temperatura de ponto de orvalho, }{ }^{\circ} \mathrm{C}
\end{aligned}
$$

\section{Método de Jensen \& Haise - (JH)}

Para regiões áridas e semiaridas, Jensen \& Haise (1963) apresentaram a seguinte equação para o cálculo da evapotranspiração:

$$
\mathrm{ET}_{\mathrm{o}}=\mathrm{R}_{\mathrm{s}}\left(0,025 \mathrm{~T}_{\text {med }}+0,08\right)
$$

em que:

$\mathrm{T}_{\text {med }}$ - é a temperatura média diária, ${ }^{\circ} \mathrm{C}$

$\mathrm{R}_{\mathrm{s}}$ - é a radiação solar global convertida em unidades de água evaporada, mm

$\mathrm{ET}_{\mathrm{o}}$ - é a evapotranspiração de referência, $\mathrm{mm} \mathrm{d}^{-1}$

Os valores de $\mathrm{R}_{\mathrm{s}}$ foram obtidos pela fórmula de Angstrom, utilizando-se os coeficientes apresentados por Silva et al. (2005).

\section{Método de Makkink - (MA)}

Por este método, a evapotranspiração de referência foi obtida por (Makkink, 1957):

$$
\mathrm{ET}_{\mathrm{o}}=\mathrm{R}_{\mathrm{s}}\left(\frac{\Delta}{\Delta+\gamma}\right)+0,12
$$

em que:

$$
\begin{aligned}
& \text { Rs - é a radiação solar convertida em unidades de } \\
& \text { água evaporada } \\
& \Delta \text { - a declinação da curva de saturação da pressão } \\
& \text { de vapor de água, } \mathrm{kPa}^{\circ} \mathrm{C}^{-1} \\
& \gamma-\text { o fator psicromértico, } \mathrm{kPa}^{\circ} \mathrm{C}^{-1}
\end{aligned}
$$

\section{Método de Priestley \& Taylor - (PT)}

Pelo método de Priestley \& Taylor, a evapotranspiração de referência, em $\mathrm{MJ} \mathrm{m}^{-2} \mathrm{~d}^{-1}$, foi obtida pela equação:

$$
\mathrm{ET}_{\mathrm{o}}=\frac{\alpha \mathrm{W}\left(\mathrm{R}_{\mathrm{n}}-\mathrm{G}\right)}{\lambda}
$$

em que:

$\alpha$ - é o parâmetro de Priestley \& Taylor

$\mathrm{R}_{\mathrm{n}}$ - o saldo de radiação, $\mathrm{MJ} \mathrm{m}^{-2} \mathrm{~d}^{-1}$

$\mathrm{G}$ - o fluxo diário de calor no solo, $\mathrm{MJ} \mathrm{m}^{-2} \mathrm{~d}^{-1}$

$\lambda$ - o calor latente de evaporação de água, $\mathrm{MJ} \mathrm{kg}^{-1}$

$\mathrm{W}$ - o fator de ponderação, que varia em função de temperatura do ar, ${ }^{\circ} \mathrm{C}$ e do fator psicrométrico, estimado por Viswanadham et al. (1991):

$$
\begin{aligned}
& \mathrm{W}=0,407+0,0147 \mathrm{~T} \quad \text { para } 0<\mathrm{T}<16{ }^{\circ} \mathrm{C} \\
& \mathrm{W}=0,483+0,01 \mathrm{~T} \quad \text { para } 16,1<\mathrm{T}<32{ }^{\circ} \mathrm{C}
\end{aligned}
$$

\section{Método do Tanque "Classe A" - (TCA)}

A evapotranspiração de referência pelo método do tanque "Classe A" foi obtida pela expressão (Doorenbos \& Pruitt, 1997):

$$
\mathrm{ET}_{\mathrm{o}}=\mathrm{K}_{\mathrm{p}} \mathrm{E}_{\mathrm{v}}
$$

em que:

$\mathrm{ET}_{\mathrm{o}}$ - é a evapotranspiração de referência, $\mathrm{mm} \mathrm{d}^{-1}$

$K_{\mathrm{P}}$ - é o coeficiente de conversão da evaporação do tanque "Classe A" em evapotranspiração de referência, que varia em função da velocidade do vento, da área de exposição vegetal relativa ao tanque e da umidade relativa do ar

$\mathrm{E}_{\mathrm{v}}$ - é a lâmina da evaporação do tanque Classe A, $\mathrm{mm} \mathrm{d}^{-1}$

\section{Coeficiente do tanque ajustado}

Obteve-se o coeficiente do tanque ajustado $\left(\mathrm{K}_{\mathrm{pa}}\right)$ pela relação entre a evaporação do tanque "Classe A" $\left(E_{v}\right)$ e a evapotranspiração de referência $\left(\mathrm{ET}_{\mathrm{o}}\right)$ através do método de Penman-Monteith (FAO/56), ou seja:

$$
\mathrm{K}_{\mathrm{pa}}=\frac{\mathrm{E}_{\mathrm{v}}}{\mathrm{ET}_{\mathrm{o}}}
$$

\section{Análise estatística}

Avaliou-se a precisão dos métodos de estimativa de $\mathrm{ET}_{\mathrm{o}}$ com base no coeficiente de correlação (r), no índice de concordância 
(d) (Willmott, 1982) e no coeficiente de confiança ou desempenho (c), o qual é o produto entre $\mathrm{r}$ e d.

$$
d=1-\left[\frac{\sum_{i=1}^{N}\left(P_{i}-O_{i}\right)}{\sum_{i=1}^{N}\left[\left(P_{i}-O_{\text {med }}\right)+\left(O_{i}-O_{\text {med }}\right)\right]^{2}}\right], \quad 0 \leq d \leq 1
$$

$\mathrm{O}$ índice $\mathrm{c}=0$ indica confiança nula e o índice $\mathrm{c}=1$ significa confiança perfeita. Na Tabela 2 se apresentam os valores do índice c e sua classificação, de acordo com Camargo \& Sentelhas (1997). Também se obteve o erro quadrático médio pela seguinte equação:

$$
\mathrm{EQM}=\left[\mathrm{N}^{-1} \sum_{\mathrm{i}=1}^{\mathrm{N}}\left(\mathrm{P}_{\mathrm{i}}-\mathrm{O}_{\mathrm{i}}\right)^{2}\right]^{0,5}
$$

em que:

$P_{i}$ - é a $E_{0}$ estimada pelo modelo a ser avaliado, $\mathrm{mm} \mathrm{d}^{-1}$

$\mathrm{O}_{\mathrm{i}}$ - é a $\mathrm{ET}_{\mathrm{o}}$ estimada pelo método padrão PenmanMonteith, $\mathrm{mm} \mathrm{d}^{-1}$

$\mathrm{O}$ - é a média de evapotranspiração de referência estimada pelo método padrão, $\mathrm{mm} \mathrm{d}^{-1}$

A Tabela 3 exibe a classificação do índice de confiança ou desempenho (c). Os valores de coeficientes de correlação encontrados foram classificados seguindo a metodologia de Hopkins (2007), de acordo com a Tabela 3.

Tabela 2. Classificação do índice de confiança ou desempenho (c), proposto por Camargo \& Sentelhas (1997)

\begin{tabular}{cc}
\hline c & Desempenho \\
$>0,90$ & Ótimo \\
0,81 a 0,90 & Muito Bom \\
0,71 a 0,80 & Bom \\
0,51 a 0,70 & Mediano \\
0,41 a 0,50 & Sofrível \\
0,31 a 0,40 & Mau \\
$\leq 0,30$ & Péssimo \\
\hline
\end{tabular}

Tabela 3. Classificação das correlações de acordo com o coeficiente de correlação (r)

$\begin{array}{cc}\text { Coeficiente de correlação }(\mathbf{r}) & \text { Classificação } \\ 0,0-0,1 & \text { Muito baixa } \\ 0,1-0,3 & \text { Baixa } \\ 0,3-0,5 & \text { Moderada } \\ 0,5-0,7 & \text { Alta } \\ 0,7-0,9 & \text { Muito alta } \\ 0,9-1,0 & \text { Quase perfeita }\end{array}$

\section{RESULTADOS E DISCUSSÃO}

Em todos os perímetros irrigados do Estado de Sergipe os maiores valores da $\mathrm{ET}_{\mathrm{o}}$ estão nos sete primeiros e sete últimos decêndios do ano e os menores entre os decêndios 13 e $22^{\circ}$, correspondentes aos períodos das estações seca e chuvosa da região (Figura 1). No período de alta demanda atmosférica da região que ocorre nesses decêndios, correspondentes aos meses de novembro, dezembro, janeiro e fevereiro, os valores de $\mathrm{ET}_{\mathrm{o}}$ oscilam entre 4,5 e 5,5 $\mathrm{mm} \mathrm{d}^{-1}$, enquanto durante o período de menor demanda atmosférica os valores de $\mathrm{ET}_{\mathrm{o}}$ oscilaram entre 2,5 e $3,5 \mathrm{~mm} \mathrm{~d}^{-1}$.

Os perímetros irrigados de Califórnia e Jacarecica apresentaram o mesmo valor do coeficiente do tanque ajustado (Kpa), ou seja, 0,92, enquanto os perímetros Jabiberi e Piauí têm valores de Kpa iguais a 1,06 e 0,90, respectivamente (Tabela 4). Os valores de Kpa são superiores ao valor médio recomendado para fora de casa de vegetação $(\mathrm{Kp}=0,85)$ e para regiões semiáridas $(\mathrm{Kp}=0,75)$, conforme recomendado por Doorenbos \& Pruitt (1977). Tais valores são baseados na bordadura de grama com valores semanais da velocidade do vento menores que $175 \mathrm{~km} \mathrm{~d}^{-1} \mathrm{e}$ umidade relativa do ar em torno de $40-70 \%$. O valor do $\mathrm{Kp}=0,75$ é utilizado, geralmente, no manejo da irrigação em vários perímetros irrigados no Nordeste do Brasil. Como nem sempre as condições de temperatura e umidade relativa do ar estabelecidas para a bordadura da grama se verificam, alguns erros podem ocorrer no dimensionamento de projetos de irrigação baseados nos coeficientes propostos por Doorenbos \& Pruitt (1977).

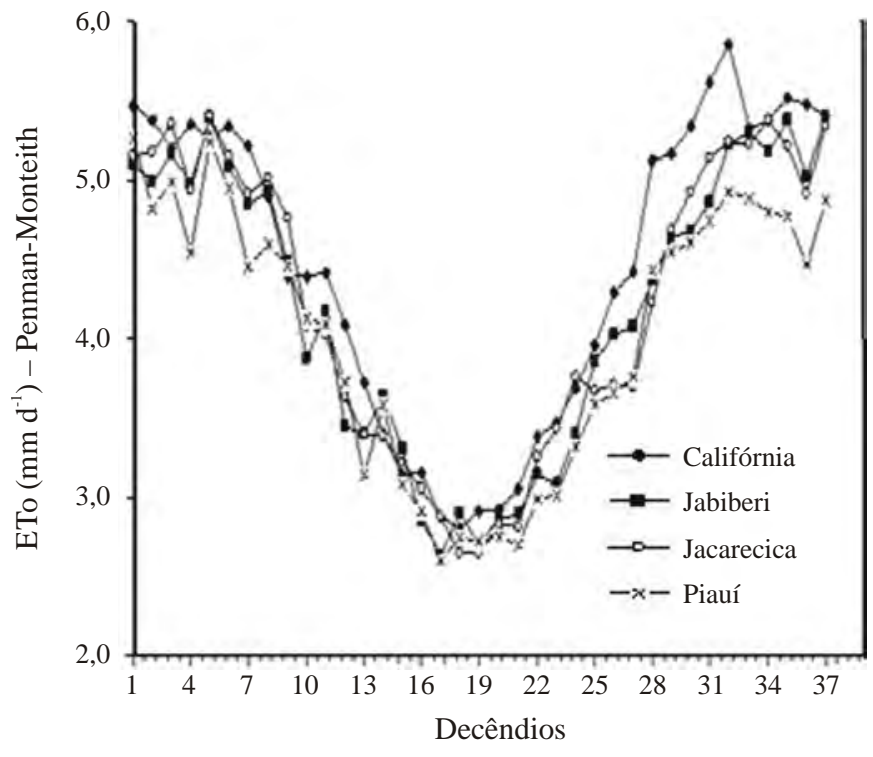

Figura 1. Valores médios decendiais da evapotranspiração de referência (período: 1989 - 1993) pelo método de Penman-M onteith nos perímetros irrigados do Estado de Sergipe

De acordo com os resultados aqui apresentados, o perímetro que apresentou o maior erro relativo foi o de Jabiberi $(28,8 \%)$ e aquele com menor erro foi o de Piauí $(15,6 \%)$. A $\mathrm{ET}_{\mathrm{o}}$ média acumulada em ano, utilizando-se o coeficiente do tanque ajustado, superestima aqueles valores, quando utilizado o coeficiente do tanque convencional. A diferença entre os valores anuais de $\mathrm{ET}_{\mathrm{o}}$ acumulados, utilizando-se os dois coeficientes do tanque, pode superar os $500 \mathrm{~mm}$, como no caso do perímetro de Jabiberi.

O relacionamento entre os valores médios decendiais da 
Tabela 4. Valores do coeficiente do tanque "Classe A" ajustados (Kpa) e ET média estimada pelo método do Tanque "Classe A", utilizando-se os coeficientes do tanque ajustado (TCA - Kpa) e o convencional (TCA - Kpc), com os seus respectivos erros relativos, e a ET o média acumulada com base no coeficiente ajustado (ET $-K p a)$ e convencional ( $\left.E T_{0}-K p c\right)$

\begin{tabular}{|c|c|c|c|c|c|c|}
\hline Perímetro & Kра & $\begin{array}{l}\text { TCA-Kpa } \\
\left(\mathrm{mm} \mathrm{d}^{-1}\right)\end{array}$ & $\begin{array}{l}\text { TCA-Kpc } \\
\left(\mathrm{mm} \mathrm{d}^{-1}\right)\end{array}$ & ER (\%) & $\begin{array}{c}\mathrm{ET}_{\mathrm{o}}-\mathrm{Kpa} \\
\left(\mathrm{mm} \mathrm{ano}^{-1}\right)\end{array}$ & $\begin{array}{c}\mathrm{ET}_{0}-\mathrm{Kpc} \\
\left(\mathrm{mm}^{-1} \mathrm{ano}^{-1}\right)\end{array}$ \\
\hline Califórnia & 0,92 & 5,6 & 4,5 & 19,6 & 2024,3 & 1656,2 \\
\hline J abiberi & 1,06 & 5,9 & 4,2 & 28,8 & 2079,2 & 1533,3 \\
\hline J acarecica & 0,92 & 5,0 & 4,1 & 18,0 & 1818,6 & 1484,4 \\
\hline Piauí & 0,90 & 4,5 & 3,8 & 15,6 & 1650,4 & 1379,4 \\
\hline
\end{tabular}

evapotranspiração de referência do tanque "Classe A", baseado no coeficiente do tanque ajustado $\left(\mathrm{ET}_{\mathrm{o}}-\mathrm{Kpa}\right)$ e o coeficiente no tanque convencional $\left(\mathrm{ET}_{\mathrm{o}}-\mathrm{Kpc}\right)$ é apresentado na Figura 2. Observa-se que os valores de $\mathrm{ET}_{\mathrm{o}}$ com o coeficiente do tanque ajustado superestimam aqueles com o coeficiente do tanque convencional para o perímetro Califórnia; entretanto, para os demais perímetros (Jabiberi, Jacarecica e Piauí) a comparação é inversa.

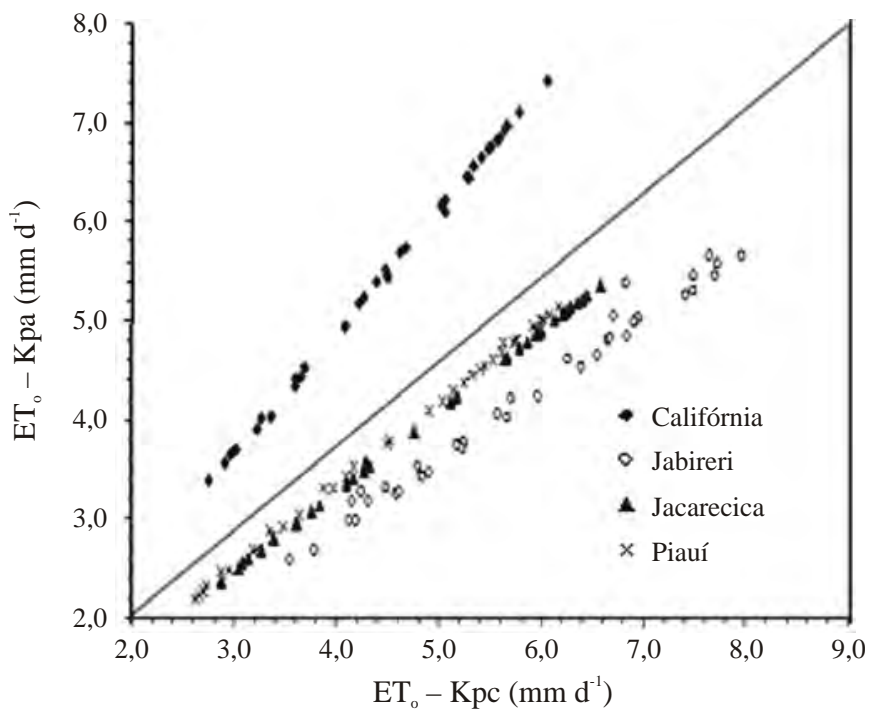

Figura 2. Relacionamento entre os valores médios decendiais da evapotranspiração de referência do tanque "Classe A" (período: 1989-1993) baseado no coeficiente do tanque ajustado (ETo - Kpa) e no coeficiente no tanque convencional (ET $-\mathrm{Kpc})$

Esses resultados sugerem que o uso do coeficiente do tanque convencional $(\mathrm{Kpc}=0,75)$ pode produzir erros no planejamento da irrigação na região estudada e, consequentemente, provocar redução da produtividade das culturas.

Os resultados da Tabela 5 evidenciam que os valores médios de $\mathrm{ET}_{\mathrm{o}}$ são menores pelo método de PM, exceto no perímetro de Califórnia; o método de MA superestimou todos os métodos chegando a atingir o valor $6,3 \mathrm{~mm}$ nos perímetros de Califórnia e Jacarecica. Os valores de $\mathrm{ET}_{\mathrm{o}}$ pelos métodos de MA e de JH superestimam praticamente todos os valores dessa variável pelo método de PM, porém no caso do método do TCA os valores de $\mathrm{ET}_{\mathrm{o}}$ tendem a subestimar aqueles com PM (Figura 3).
Tabela 5. Valores médios da evapotranspiração de referência estimados pelos métodos de Hargreaves (HA), Jensen-Haise (JH), Linacre (LI), Makkink (MA), Prestley \& Taylor (PT), Penman-Monteith (PM)

\begin{tabular}{lcccccc}
\hline Perímetro & (HA) & (J H) & (LI) & (MA) & (PT) & (PM) \\
Califórnia & 4,8 & 6,0 & 4,8 & 6,3 & 4,7 & 4,4 \\
J abiberi & 4,2 & 5,1 & 5,4 & 5,4 & 4,2 & 4,2 \\
J acarecica & 4,1 & 5,8 & 4,0 & 6,3 & 4,7 & 4,2 \\
Piauí & 4,1 & 5,7 & 4,1 & 6,2 & 4,6 & 4,0 \\
\hline
\end{tabular}

Os métodos que apresentaram melhor correlação com o PM no perímetro de Califórnia foram os de JH e PT, com coeficiente de correlação (r) de 0,95 e 0,92 respectivamente, enquanto o de pior relacionamento foi com o método de TCA, com valor de 0,60, que também apresentou o pior índice de desempenho (c), com 0,58 (Tabela 6). O método TCA foi o único classificado como mediano, enquanto os demais foram avaliados como muito bom. Os métodos que utilizaram a radiação solar incidente como variável de entrada no modelo apresentaram os maiores valores de "r", "d" e "c" nesse perímetro; além disso, todos os métodos superestimam os valores da evapotranspiração determinada por PM, exceto o método do TCA, cujo valor do coeficiente de correlação é o menor dentre todos os métodos analisados. Por outro lado, o método HA apresentou o menor erro quadrático médio $\left(0,71 \mathrm{~mm} \mathrm{~d}^{-1}\right)$ enquanto o maior valor desse erro foi para o método de MA $\left(2,04 \mathrm{~mm} \mathrm{~d}^{-1}\right)$.

De acordo com a Figura 4 e exceto para o método do TCA, os valores de $\mathrm{ET}_{\mathrm{o}}$ pelo método de $\mathrm{PM}$ são superiores àqueles obtidos pelos demais métodos. $\mathrm{O}$ menor relacionamento entre os métodos no perímetro de Jabiberi foi com o do TCA $(0,41)$ e o maior com o de HA $(0,88)$. Borges \& Mendiondo (2007), comparando o método FAO Penman-Monteith com a equação de Hargreaves, encontraram índices de confiança superiores a 0,995 para a bacia do rio Jacupiranga, SP, Brasil.

O perímetro irrigado Jacarecica foi o que apresentou os maiores índices de concordância, com todos os coeficientes de correlação dentro da faixa de alta correlação (Figura 5). Observa-se, ainda, que os métodos TCA, HA e LI subestimam os valores de $\mathrm{ET}_{\mathrm{o}}$ pelo método PM, enquanto os métodos PT, MA e JH superestimam os valores da $\mathrm{ET}_{\mathrm{o}}$ por esse método padrão da FAO. O índice de desempenho desse perímetro apresentou a melhor classificação, sendo os métodos JH, PT classificados como Ótimos e o método HA como Muito Bom; já os métodos de LI, MA e TCA foram classificados como Bom (Tabela 6).

$\mathrm{A} \mathrm{ET}_{\mathrm{o}}$ média estimada que mais se aproximou da média observada foi obtida pelo método HA, com o valor de $4,09 \mathrm{~mm} \mathrm{~d}^{-1}$. Em relação ao erro quadrático médio, o método que obteve o maior valor foi o de $\mathrm{MA}\left(2,32 \mathrm{~mm} \mathrm{~d}^{-1}\right)$ e o que apresentou o menor valor foi o método PT $\left(0,61 \mathrm{~mm} \mathrm{~d}^{-1}\right)$. O perímetro irrigado Piauí também apresentou altos coeficientes de determinação entre os métodos analisados, exceto para o TCA (Figura 6).

Observa-se na, Tabela 6, que o índice de correlação variou de "Muito Alto" a "Moderado" no perímetro de Jabiberi. Os métodos de PM e de PT obtiveram o mesmo valor de $\mathrm{ET}_{\mathrm{o}}\left(4,18 \mathrm{~mm} \mathrm{~d}^{-1}\right)$. O método que obteve maior erro foi $\mathrm{o}$ 
A.

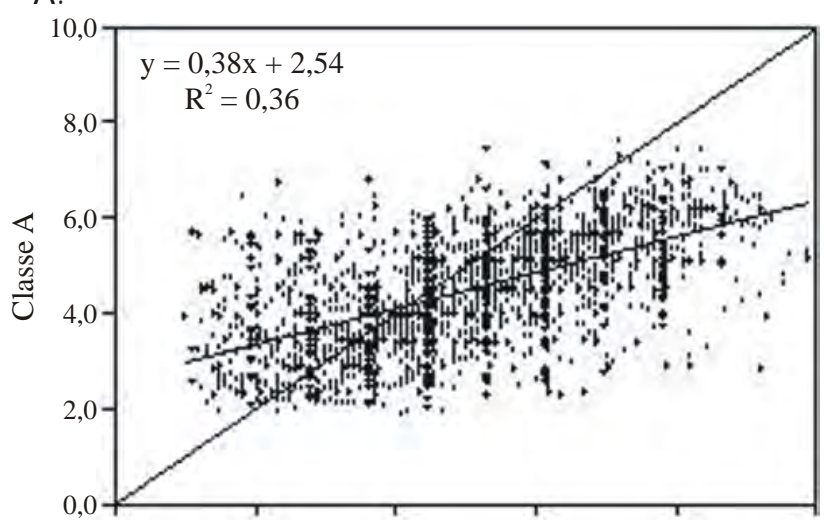

C.

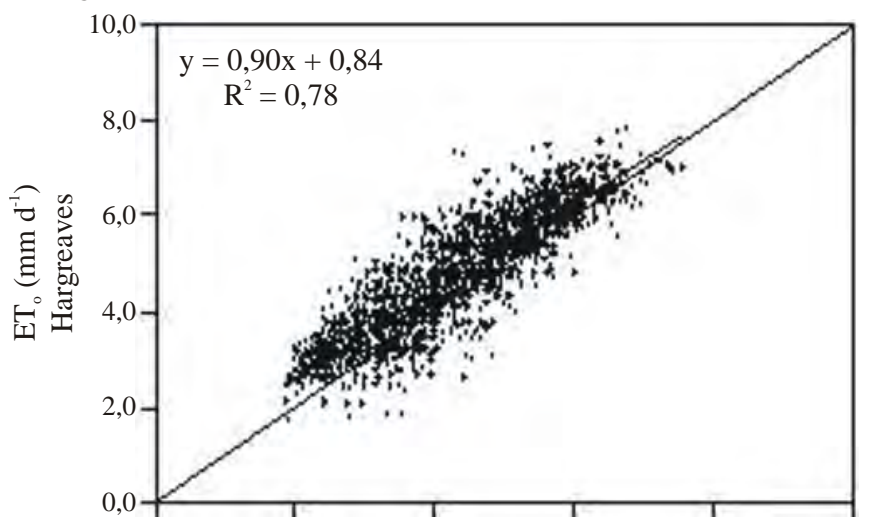

$E$

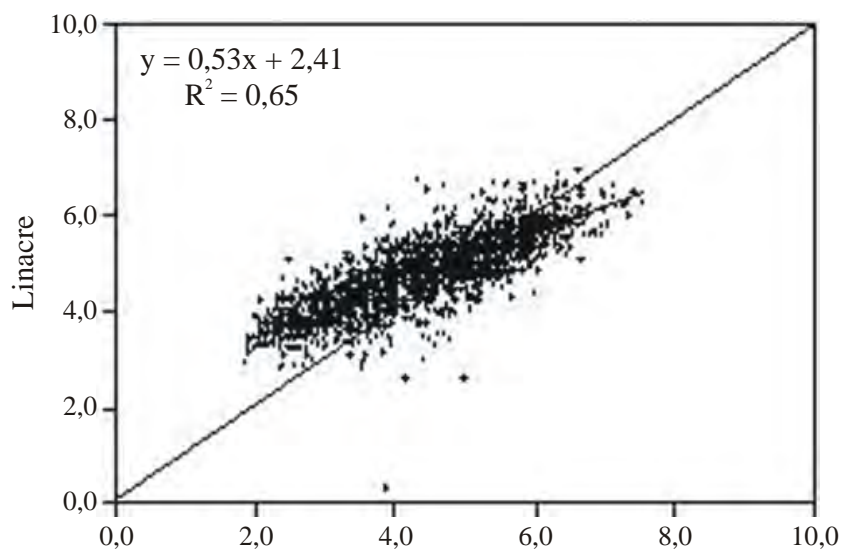

B.

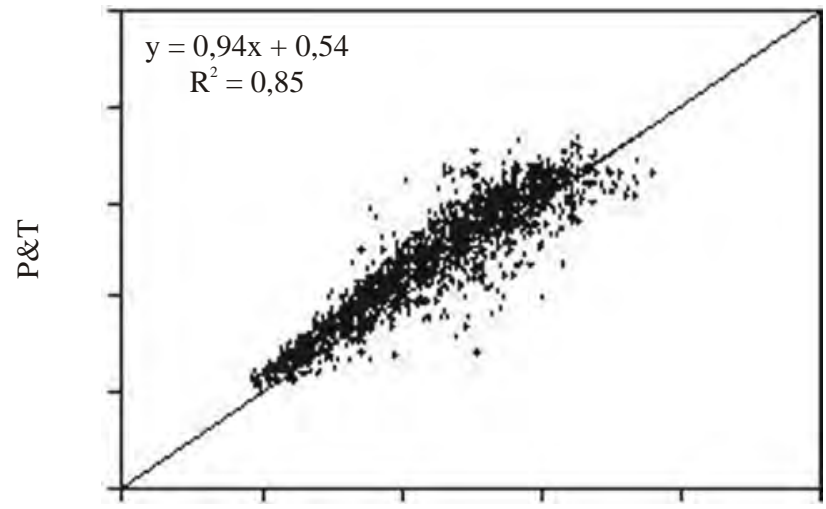

D.

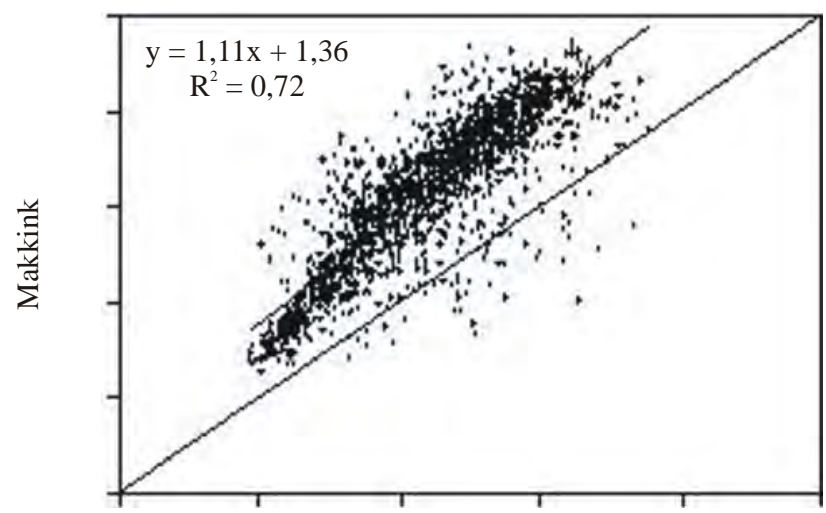

F.

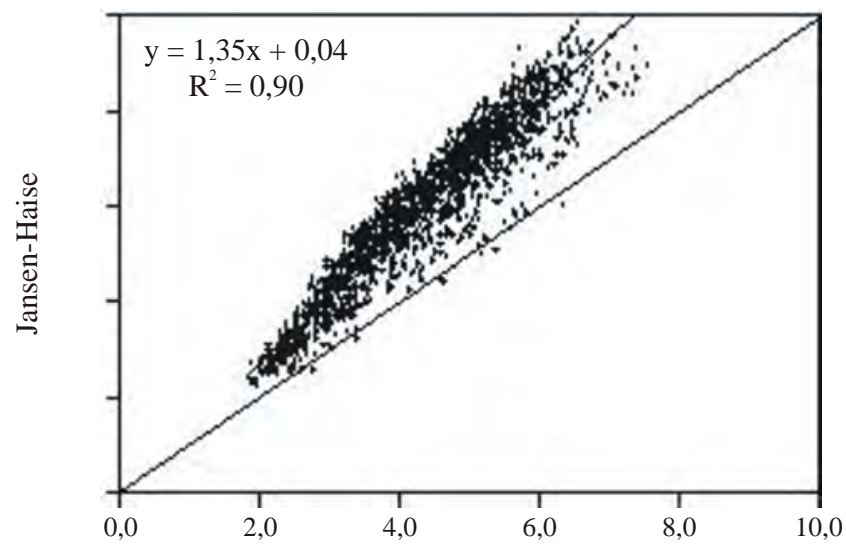

$\mathrm{ET}_{\mathrm{o}}\left(\mathrm{mm} \mathrm{d}^{-1}\right)$ - Penman-Monteith

Figura 3. Comparação da evapotranspiração de referência diária entre o método Penman-M onteith e os métodos: (A) tanque "Classe A", (B) Priestley \& Taylor, (C) Hargreaves, (D) Makkink, (E) Linacre e (F) Jensen-Haise, no perímetro irrigado Califórnia 
A.

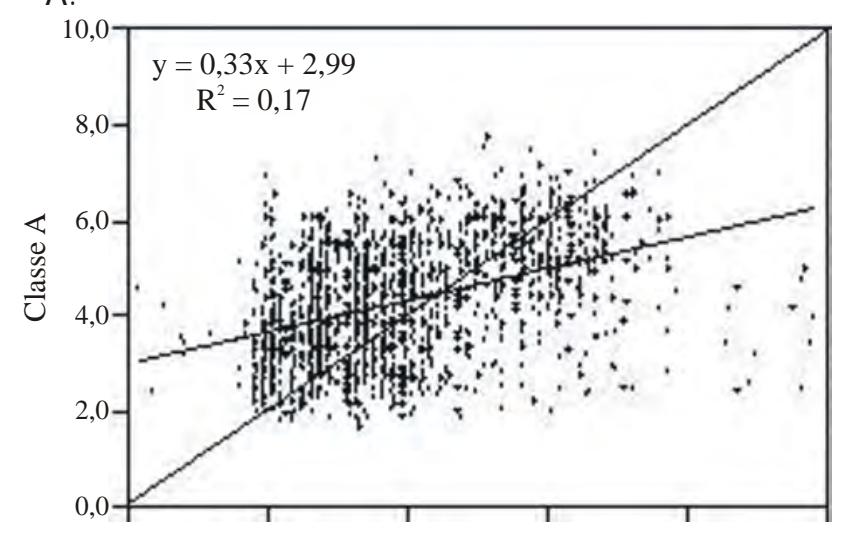

C.

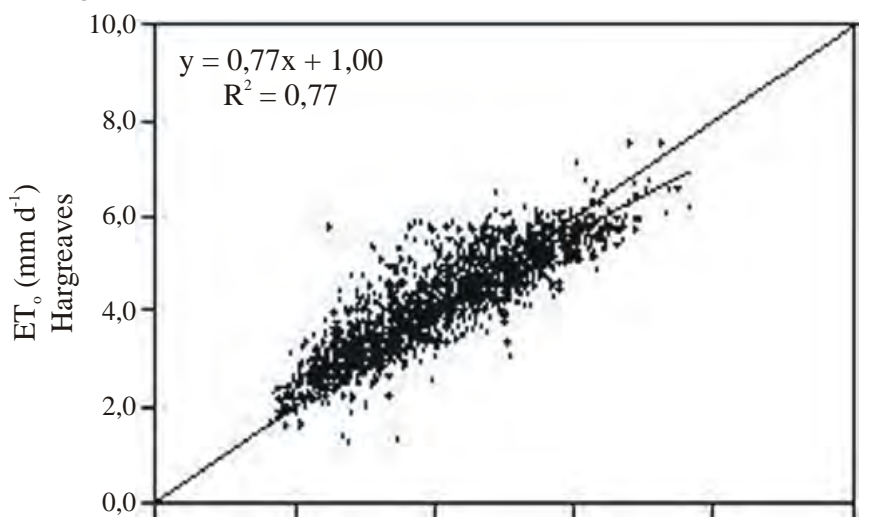

$E$

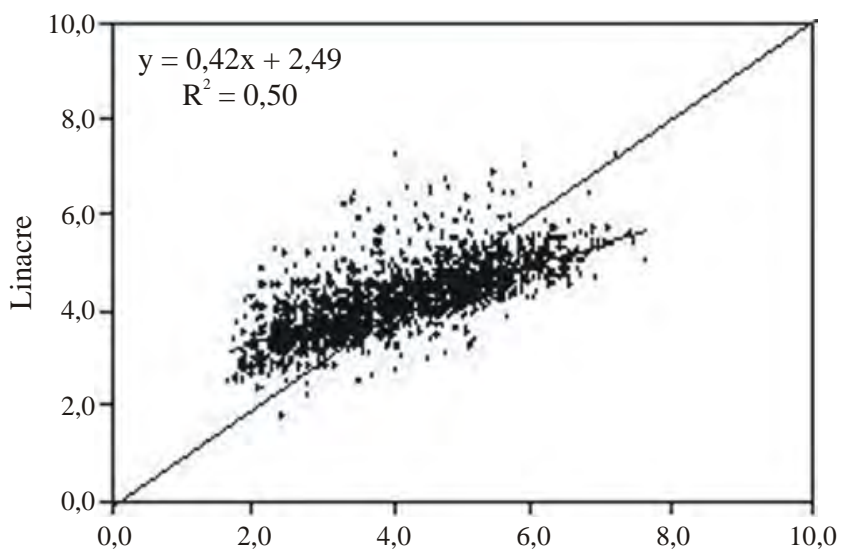

B.

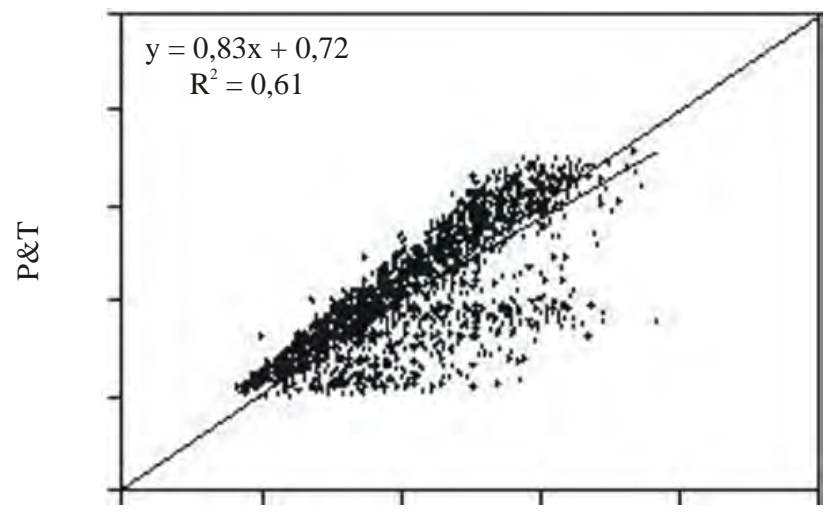

D.

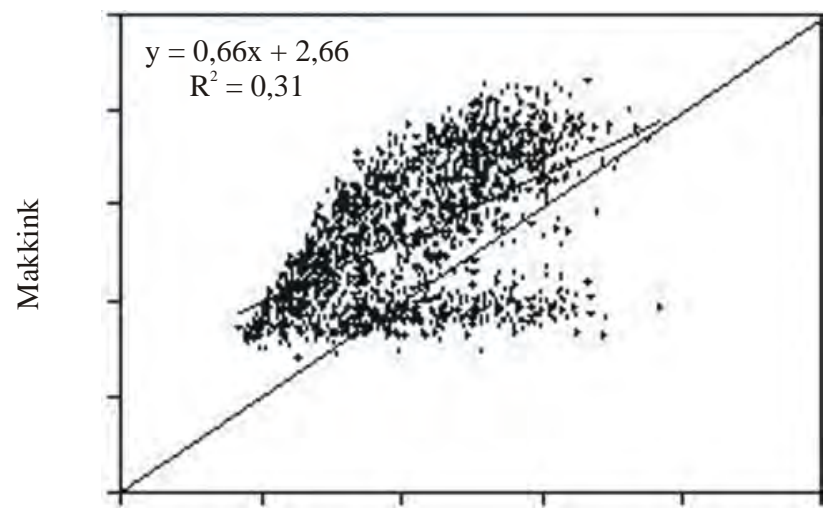

F.

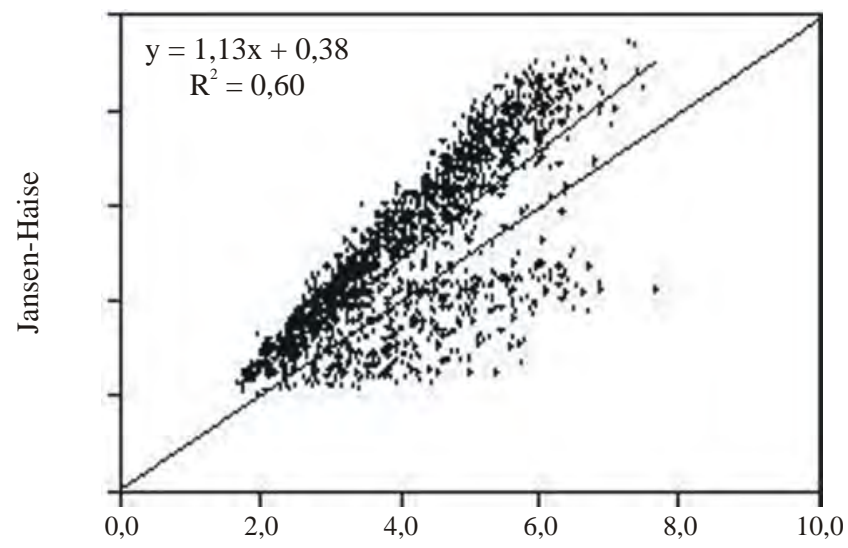

$\mathrm{ET}_{\mathrm{o}}\left(\mathrm{mm} \mathrm{d}^{-1}\right)-$ Penman-Monteith

Figura 4. Comparação da evapotranspiração de referência diária entre o método Penman-M onteith e os métodos: (A) tanque "Classe A", (B) Priestley \& Taylor, (C) Hargreaves, (D) Makkink, (E) Linacre e (F) Jensen-Haise, no perímetro irrigado Jabiberi 
A.

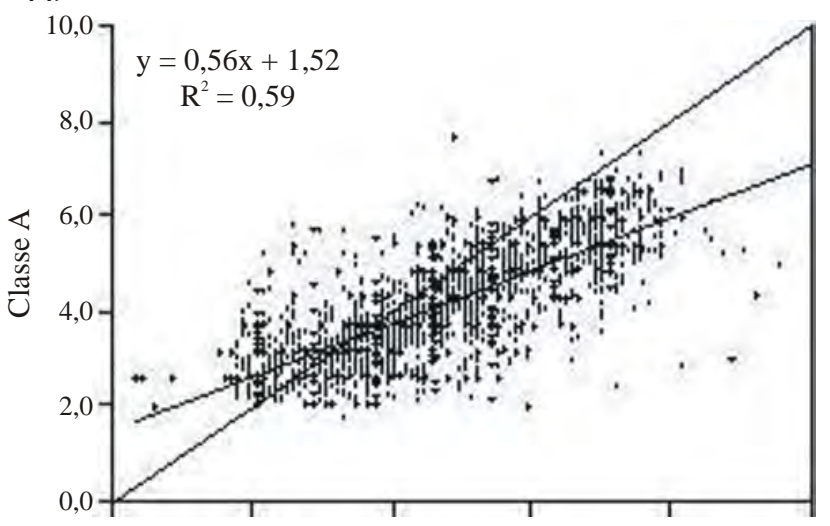

C.

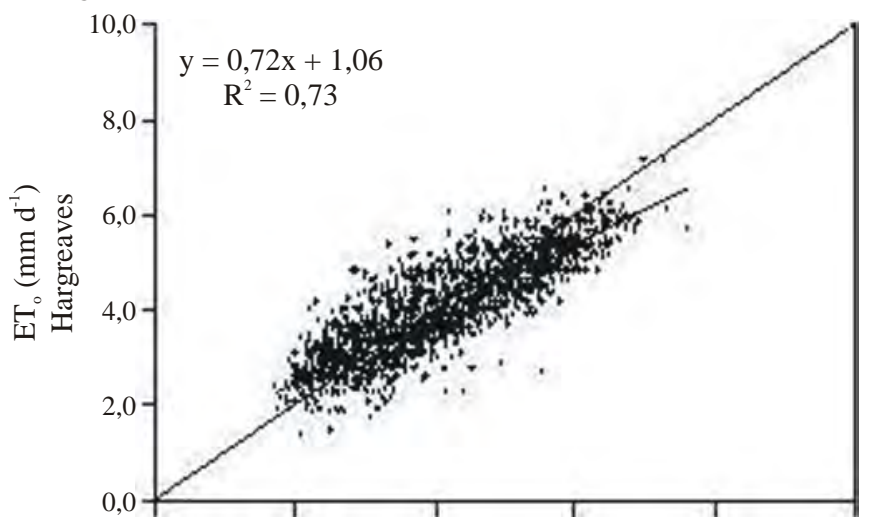

E.

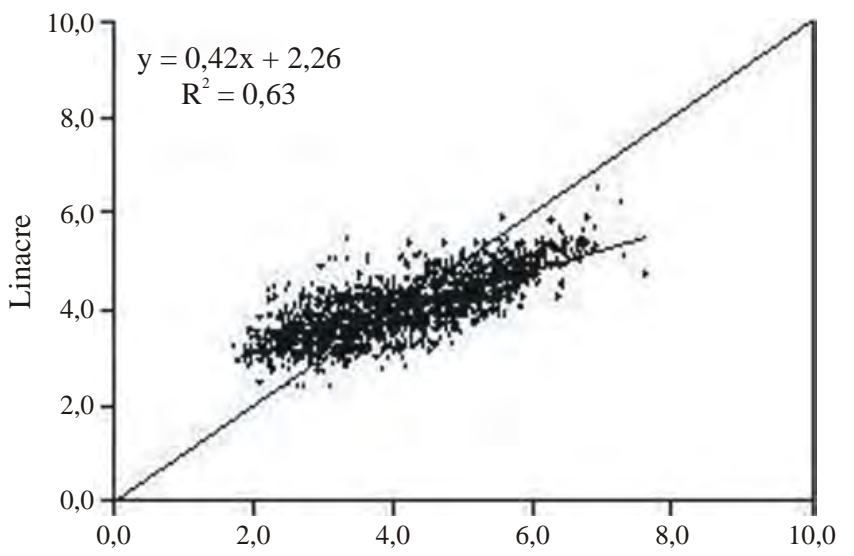

B.

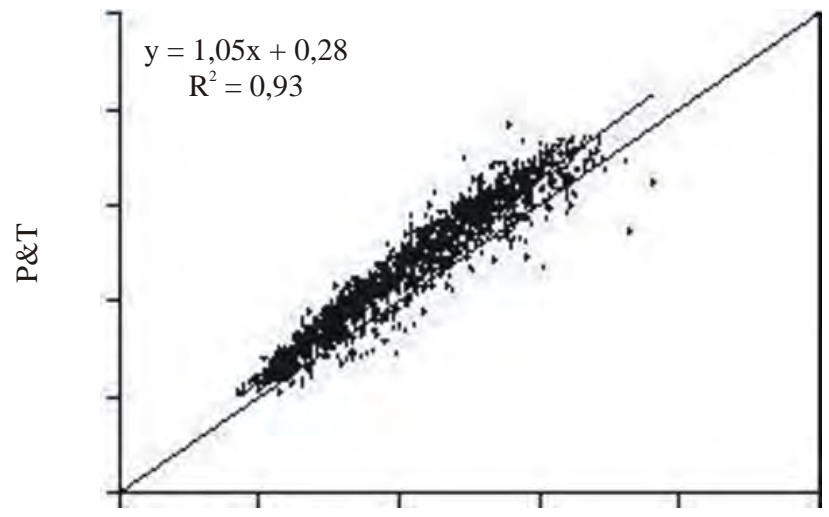

D.

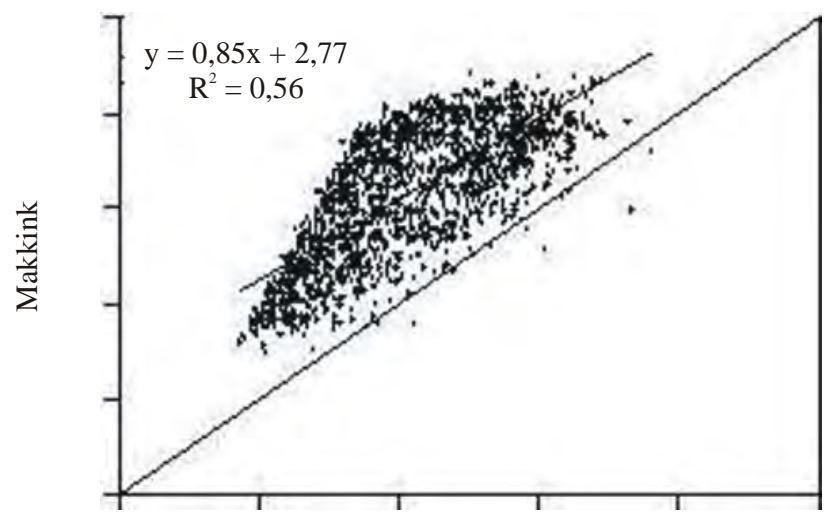

F.

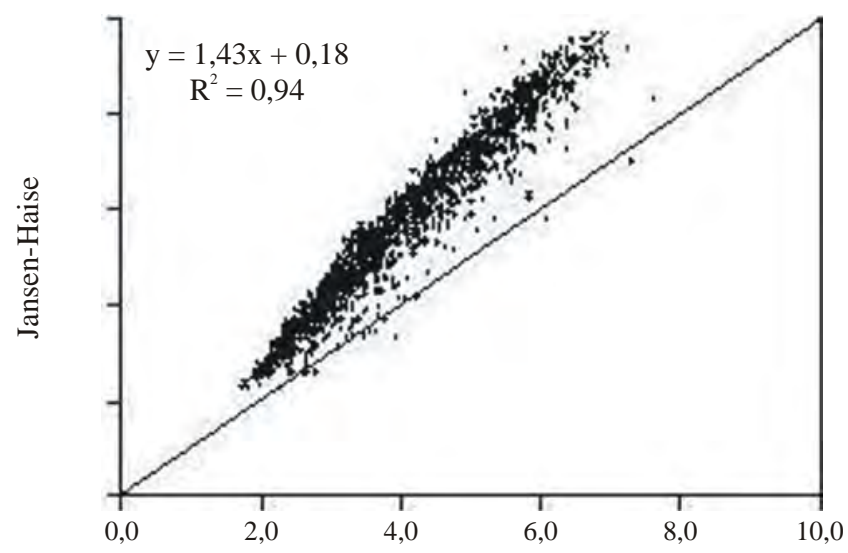

$\mathrm{ET}_{\mathrm{o}}\left(\mathrm{mm} \mathrm{d}^{-1}\right)-$ Penman-Monteith

Figura 5. Comparação da evapotranspiração de referência diária entre o método Penman-M onteith e os métodos: (A) tanque "Classe $A$ ", (B) Priestley \& Taylor, (C) Hargreaves, (D) Makkink, (E) Linacre e (F) Jensen-Haise, no perímetro irrigado Jacarecica 
A.

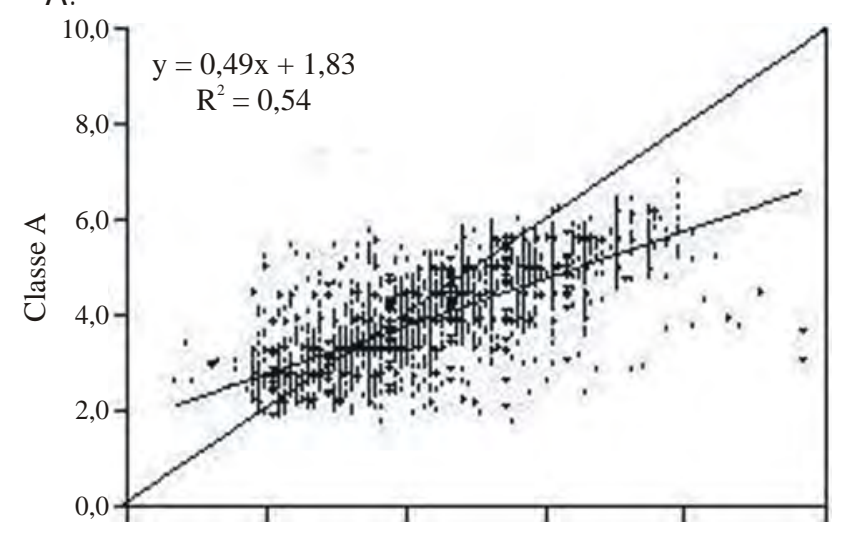

C.

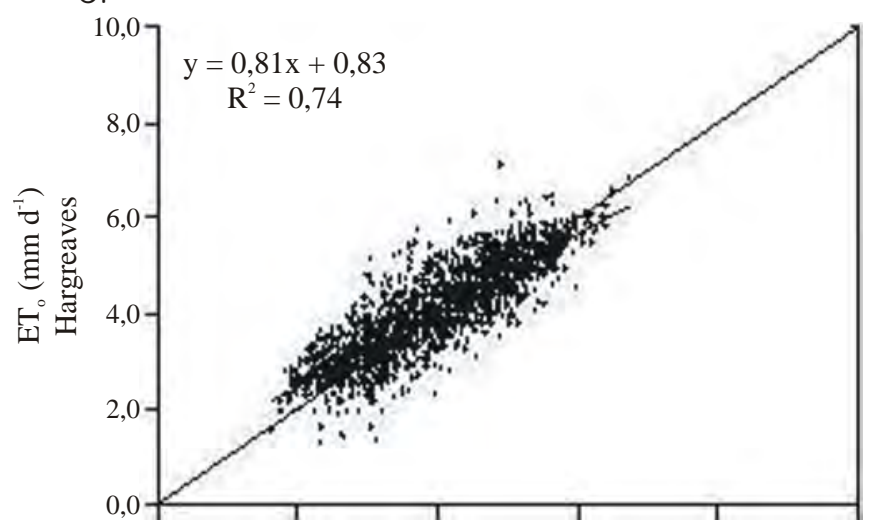

E.

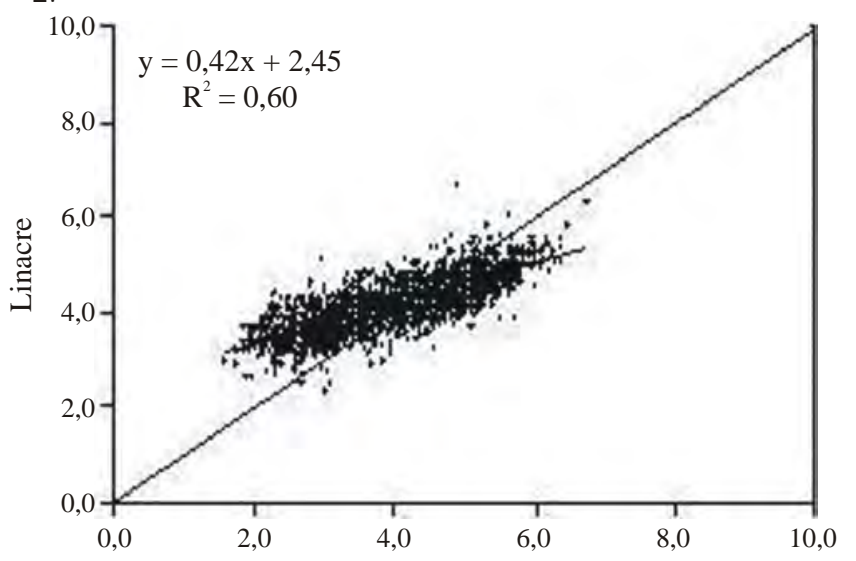

B.

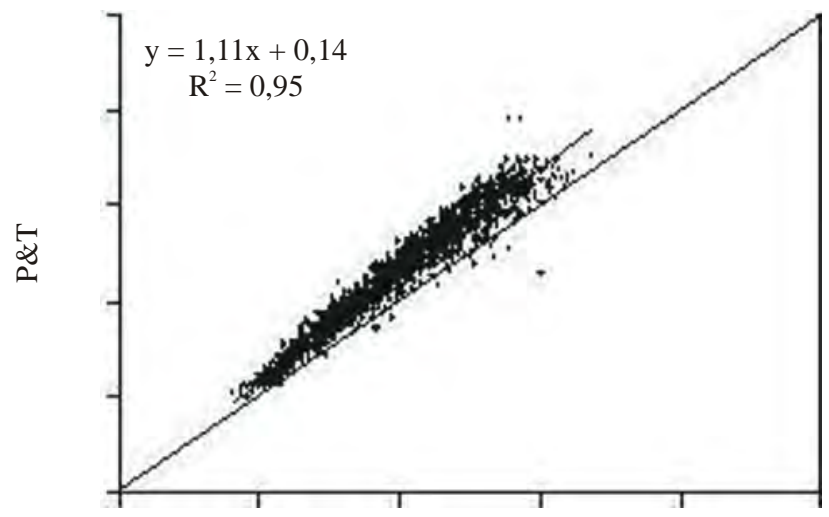

D.

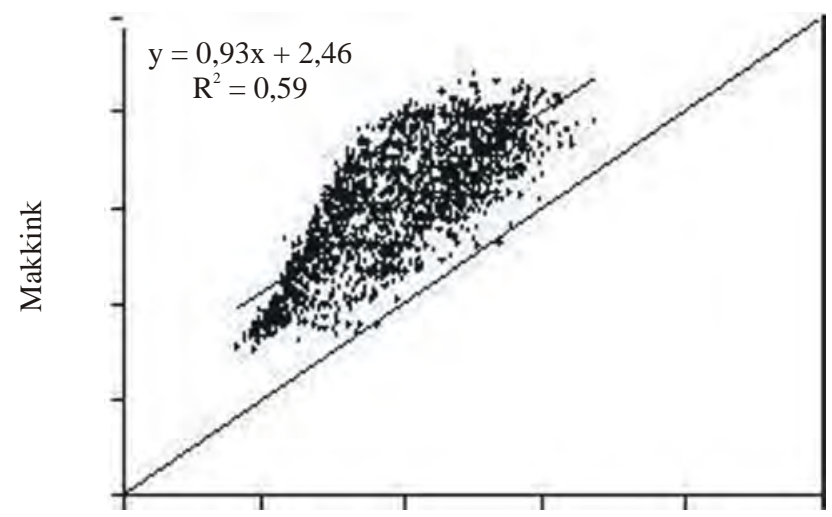

F.

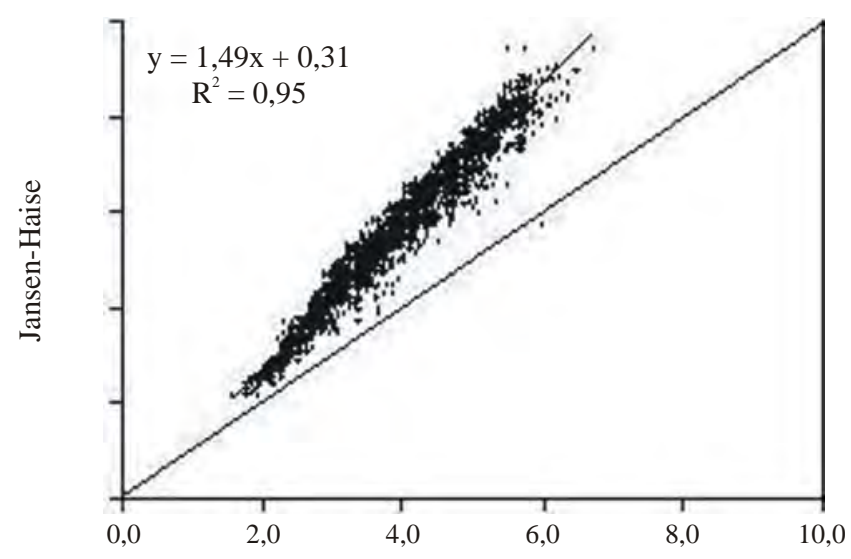

$\mathrm{ET}_{\mathrm{o}}\left(\mathrm{mm} \mathrm{d}^{-1}\right)$ - Penman-Monteith

Figura 6. Comparação da evapotranspiração de referência diária entre o método Penman-M onteith e os métodos: (A) tanque "Classe A", (B) Priestley \& Taylor, (C) Hargreaves, (D) Makkink, (E) Linacre e (F) Jensen-Haise, no perímetro irrigado Piauí 
Tabela 6. Valores do erro quadrático médio (EQ M), índice de concordância (d), coeficiente de correlação (r) e do índice de desempenho (c) obtidos pelos métodos de Hargreaves, Jensen-Haise, Linacre, Makkink, Prestley \& Taylor a Tanque "Classe A" quando comparados com o método de Penman-M onteith para os perímetros irrigados de Califórnia, Jacarecica, Jebiberi e Piaúi; Pi representa o valor médio da ET estimada por cada método e $0_{i}$ é 0 valor médio da $\mathrm{ET}_{0}$ (Penman-M onteith)

\begin{tabular}{|c|c|c|c|c|c|c|c|}
\hline Método & $\mathbf{P}_{\mathrm{i}}$ & $0_{i}$ & EQM & $d$ & $r$ & c & Critério \\
\hline \multicolumn{8}{|c|}{ Perímetro irrigado de Califórnia } \\
\hline Hargreaves & 4,84 & 4,40 & 0,71 & 0,99 & 0,88 & 0,88 & Muito Bom \\
\hline J ensen-Haise & 6,03 & 4,40 & 1,73 & 0,97 & 0,95 & 0,92 & Ótimo \\
\hline Linacre & 4,77 & 4,40 & 0,80 & 0,99 & 0,81 & 0,80 & Muito Bom \\
\hline Makkink & 6,30 & 4,40 & 2,04 & 0,97 & 0,85 & 0,82 & Muito Bom \\
\hline Prestley \& Taylor & 4,72 & 4,40 & 0,55 & 1,00 & 0,92 & 0,92 & Ótimo \\
\hline Classe A & 5,09 & 4,40 & 1,75 & 0,97 & 0,60 & 0,58 & Mediano \\
\hline \multicolumn{8}{|c|}{ Perímetro irrigado de J acarecica } \\
\hline Hargreaves & 4,09 & 4,21 & 0,64 & 0,99 & 0,85 & 0,85 & Muito Bom \\
\hline J ensen-Haise & 5,84 & 4,21 & 1,76 & 0,97 & 0,97 & 0,94 & Ótimo \\
\hline Linacre & 4,04 & 4,21 & 0,82 & 0,99 & 0,79 & 0,79 & Bom \\
\hline Makkink & 6,34 & 4,21 & 2,32 & 0,95 & 0,75 & 0,71 & Bom \\
\hline Prestley \& Taylor & 4,71 & 4,21 & 0,61 & 1,00 & 0,96 & 0,96 & Ótimo \\
\hline Classe A & 4,94 & 4,21 & 1,39 & 0,98 & 0,77 & 0,75 & Bom \\
\hline \multicolumn{8}{|c|}{ Perímetro irrigado de J abiberi } \\
\hline Hargreaves & 4,21 & 4,18 & 0,58 & 1,00 & 0,88 & 0,87 & Muito Bom \\
\hline J ensen-Haise & 5,09 & 4,18 & 1,45 & 0,98 & 0,77 & 0,76 & Bom \\
\hline Linacre & 4,23 & 4,18 & 0,87 & 0,99 & 0,71 & 0,70 & Bom \\
\hline Makkink & 5,42 & 4,18 & 1,76 & 0,97 & 0,56 & 0,54 & Mediano \\
\hline Prestley \& Taylor & 4,18 & 4,18 & 0,83 & 0,99 & 0,78 & 0,77 & Bom \\
\hline Classe A & 3,55 & 4,18 & 1,95 & 0,94 & 0,41 & 0,39 & Mau \\
\hline \multicolumn{8}{|c|}{ Perímetro irrigado de Piauí } \\
\hline Hargreaves & 4,07 & 4,01 & 0,58 & 1,00 & 0,86 & 0,86 & Muito Bom \\
\hline J ensen-Haise & 5,67 & 4,01 & 1,77 & 0,97 & 0,97 & 0,94 & Ótimo \\
\hline Linacre & 4,13 & 4,01 & 0,73 & 0,99 & 0,77 & 0,77 & Bom \\
\hline Makkink & 6,20 & 4,01 & 2,33 & 0,95 & 0,77 & 0,73 & Bom \\
\hline Prestley \& Taylor & 4,59 & 4,01 & 0,64 & 0,99 & 0,97 & 0,97 & Ótimo \\
\hline Classe A & 4,62 & 4,01 & 1,35 & 0,98 & 0,73 & 0,72 & Bom \\
\hline
\end{tabular}

TCA, com o valor de $1,95 \mathrm{~mm} \mathrm{~d}^{-1}$. Com referência ao índice de desempenho (c), o método de HA foi classificado como "Muito Bom", enquanto os de JH e PT, como "Ótimo" e os de LI, MA e do TCA, como "Bom".

Obteve-se, para o perímetro irrigado Piauí, resultado muito semelhante ao do perímetro Jacarecica. Os melhores índices de concordância ficaram dentro da faixa de Muito alto (Tabela 6); este perímetro apresentou excelente índice de desempenho, sendo os métodos JH e PT classificados "Ótimos"; já o método HA foi avaliado Muito Bom e os métodos LI, MA e TCA, "Bom".

Os métodos que obtiveram os menores erros foram o HA e PT, cujos valores foram 0,58 e $0,64 \mathrm{~mm} \mathrm{~d}^{-1}$, respectivamente. O método que obteve maior erro foi o de MA, com o valor de $2,33 \mathrm{~mm} \mathrm{~d}^{-1}$. O método de HA apresentou valores de $\mathrm{ET}_{\mathrm{o}}$ muito próximos daqueles do método de PM.

\section{CONCLUSÕES}

1. A utilização do coeficiente do tanque "Classe A" con- vencional $(0,75)$ pôde produzir erros no manejo da irrigação, nos perímetros irrigados do Estado de Sergipe, e ultrapassar o valor acumulado no ano, em mais de $500 \mathrm{~mm}$, quando comparado com a $\mathrm{ET}_{\mathrm{o}}$ baseada no coeficiente do tanque ajustado.

2. Para os perímetros irrigados do Estado de Sergipe, os valores da $\mathrm{ET}_{\mathrm{o}}$ pelos métodos do Tanque "Classe A", Hargreaves, Prestley \& Taylor, Jensen \& Haise e do Linacre se distanciam, nessa ordem, daqueles obtidos com o método padrão de Penman-Monteith;

3. Os métodos de obtenção da evapotranspiração que incorporam o saldo de radiação solar são os que apresentam os valores mais próximos daqueles obtidos pelo método de PM.

\section{LITERATURA CITADA}

Allen, R. G.; Pereira; L. S.; Raes, D. Crop evapotranspiration. Guidelines for computing crop water requirements. Rome: FAO, 1998. 300p. Irrigation and Drainage Paper 56.

Berlato, M. A.; Molion, L. C. B. Evaporação e evapotranspiração. Porto Alegre: IPAGRO/Secretaria de Agricultura, 1981. 95p. Boletim Técnico 7

Borges, A. C.; Mendiondo, E. M. Comparação entre equações empíricas para estimativa da evapotranspiração de referência na Bacia do Rio Jacupiranga. Revista Brasileira de Engenharia Agrícola e Ambiental, v.11, n.3, p.293-300, 2007.

Camargo, A. P.; Sentelhas, P. C. Avaliação do desempenho de diferentes métodos de estimativa da evapotranspiração potencial no estado de São Paulo, Brasil. Revista Brasileira de Agrometeorologia, v.5, n.1, p.89-97, 1997.

Campos, J. H. B. C.; Silva, V. de P. R.; Azevedo, P. V. de; Borges, C. J. R.; Soares, J. M.; Moura, M. S. B.; Silva, B. B da. Evapotranspiração e produtividade da mangueira sob diferentes tratamentos de irrigação. Revista Brasileira de Engenharia Agrícola e Ambiental, v.12, n.2, p.150-156, 2008.

Cavalcanti, E. P.; Silva, V. de P. R.; Sousa, F. de A. S. Programa computacional para a estimativa da temperatura do ar para a Região Nordeste do Brasil. Revista Brasileira de Engenharia Agrícola e Ambiental, v.10, n.1, p.140-147, 2006.

Doorenbos, J.; Pruitt, W. O. Guidelines for predicting crop water requirements. 2.ed. Rome: FAO, 1977. 156p. FAO Irrigation and Drainage Paper, 24.

Hargreaves, G. H. Estimation of potential and crop evapotranspiration. Transactions of the ASAE, v.17, n.174, p.701-704, 1974.

Hopkins, W. G. Correlation coefficient. http://www. sportsci. org/ resource/stats /correl. html. 12 Mar. 2007.

Jensen, M. E.; Haise, H. R. Estimating evapotranspiration from solar radiation. Journal of Irrigation and Drain Engineering. Bulletin of the American Meteorological Society, v.89, p.15-41, 1963.

Linacre, E. T. A simple formula for estimating evapotranspiration rates in various climates, using temperature data alone. Agricultural Meteorology, v.18, p.409-424, 1977.

Makkink, G. F. Ekzameno de la formula de Penman. Neth. Journal of Agricultural Science, v.5, n.1, p.290-305, 1957. 
Penman, H. L. Natural evaporation from open water, bare soil and grass. Proceedings of the Royal Society, v.193, n.1, p.454-465, 1948.

Priestley, C. H. B.; Taylor, R. J. On the assessment of surface heat flux and evaporation using large-scale parameters. Monthly Weather Review, v.100, p.81-92, 1972.

Silva, V. de P. R. On climate variability in Northeast of Brazil. Journal of Arid Environments, v.1, n.58, p.575-596, 2004.

Silva, V. de P. R.; Belo Filho, A. F.; Silva, B. B. da; Campos, J. H. B. C. Desenvolvimento de um sistema de estimativa da evapotranspiração de referência. Revista Brasileira de Engenharia Agrícola e Ambiental, v.9, n.4, p.547-553, 2005.

Silva, V. de P. R.; Campos, J. H. B. C.; Azevedo, P. V. de. Wateruse efficiency and evapotranspiration of mango orchard grown in northeastern region of Brazil. Scientia Horticulturae, v.1, n.120, p.467-472, 2009.

Silva, V. de P. R.; Cavalcanti, E. P.; Nascimento, M. G.; Campos, J. H. C. Análises da precipitação pluvial no Estado da Paraíba com base na teoria da entropia. Revista Brasileira de Engenharia Agrícola e Ambiental, v.7, n.2, p.269-274, 2003.
Silva, V. de P. R.; Guedes, M. J. F.; Lima, W. F. A.; Campos, J. H. B. C. Modelo de previsão de rendimento de culturas de sequeiro, no semi-árido do Nordeste do Brasil. Revista Brasileira de Engenharia Agrícola e Ambiental, v.6, n.1, p.83-87, 2002.

Stone, L. F.; Silveira, P. M. Determinação da evapotranspiração para fins de irrigação. Brasília: Embrapa-CNPAF, 1995. 49p, Documento 55.

Suleiman, A. A.; Hoogenboom, G. Comparison of Priestley-Taylor and FAO-56 Penman-Monteith for daily reference evapotranspiration estimation in Georgia. Journal of Irrigation and Drainage Engineering, v.33, n.2, 175-182. 2007.

Thornthwaite, C. W. An approach toward a rational classification of climate. Geographical Review, v.38, n.1, p.55-94, 1948.

Viswanadham, Y.; Silva Filho, V. P.; Andre, R. G. B. The Priestley-Taylor parameter for the Amazon forest. Forest Ecology Management, v.38, n.1, p.211-225, 1991.

Willmott, C. J. Some comments on the evaluation of model performance. Bulletin of the American Meteorological Society, v.63, n.11, p.1309-1313, 1982. 